\title{
Congenital diaphragmatic hernia: a narrative review of controversies in neonatal management
}

\author{
Michelle J. Yang ${ }^{1}$, Katie W. Russell ${ }^{2}$, Bradley A. Yoder ${ }^{1}$, Stephen J. Fenton ${ }^{2} \wedge$ \\ ${ }^{1}$ Division of Neonatology, University of Utah School of Medicine, Salt Lake City, UT, USA; ${ }^{2}$ Division of Pediatric Surgery, University of Utah \\ School of Medicine, Salt Lake City, UT, USA \\ Contributions: (I) Conception and Design: KW Russell, SJ Fenton; (II) Administrative support: KW Russell; (III) Provision of study materials: All \\ authors; (IV) Collection and assembly of data: All authors; (V) Data analysis and interpretation: All authors; (VI) Manuscript writing: All authors; (VII) \\ Final approval of manuscript: All authors. \\ Correspondence to: Stephen J. Fenton. 100 N Mario Capecchi Drive, Suite 3800, Salt Lake City, Utah 84113, USA. Email: stephen.fenton@hsc.utah.edu.
}

\begin{abstract}
The consequences of most hernias can be immediately corrected by surgical repair. However, this isn't always the case for children born with a congenital diaphragmatic hernia. The derangements in physiology encountered immediately after birth result from pulmonary hypoplasia and hypertension caused by herniation of abdominal contents into the chest early in lung development. This degree of physiologic compromise can vary from mild to severe. Postnatal management of these children remains controversial. Although heavily studied, multi-institutional randomized controlled trials are lacking to help determine what constitutes best practice. Additionally, the results of the many studies currently within the literature that have investigated differing aspect of care (i.e., inhaled nitric oxide, ventilator type, timing of repair, role of extracorporeal membrane oxygenation, etc.) are difficult to interpret due to the small numbers investigated, the varying degree of physiologic compromise, and the contrasting care that exists between institutions. The aim of this paper is to review areas of controversy in the care of these complex kids, mainly: the use of fraction of inspired oxygen, surfactant therapy, gentle ventilation, mode of ventilation, medical management of pulmonary hypertension (inhaled nitric oxide, sildenafil, milrinone, bosentan, prostaglandins), the utilization of extracorporeal membrane oxygenation, and the timing of surgical repair.
\end{abstract}

Keywords: Hernias; diaphragmatic; congenital; treatment; medicine; surgery

Submitted May 18, 2020. Accepted for publication Oct 16, 2020.

doi: $10.21037 /$ tp-20-142

View this article at: http://dx.doi.org/10.21037/tp-20-142

A congenital diaphragmatic hernia $(\mathrm{CDH})$ results from the inadequate formation of the diaphragm during embryogenesis and causes a cascade of events which can present in a newborn child varying clinically from mild to very severe to fatal. The incidence of $\mathrm{CDH}$ is 1 in 2,500 to 1 in 3,500 live births and occurs $90 \%$ of the time in the posterolateral aspect of the diaphragm known as a Bochdalek hernia with over $85 \%$ occurring on the left side (1). The diaphragmatic defect in the embryo allows for abdominal viscera to enter the thoracic cavity causing a mass effect on the developing lungs resulting in pulmonary hypoplasia and pulmonary hypertension. The degree of clinical severity is often proportional to the size of the defect (Figure 1) (2,3). Although the consequences of other hernias can be avoided when repaired surgically, often there is no quick fix to this underlying dysgenesis of the lungs. In fact, past review of immediate repair demonstrated a worsening in the physiology of $\mathrm{CDH}$ neonates, which helped shift repair to a more delayed approach (4). These issues are most often addressed through medical management

\footnotetext{
$\wedge$ ORCID: 0000-0003-3262-5702.
} 

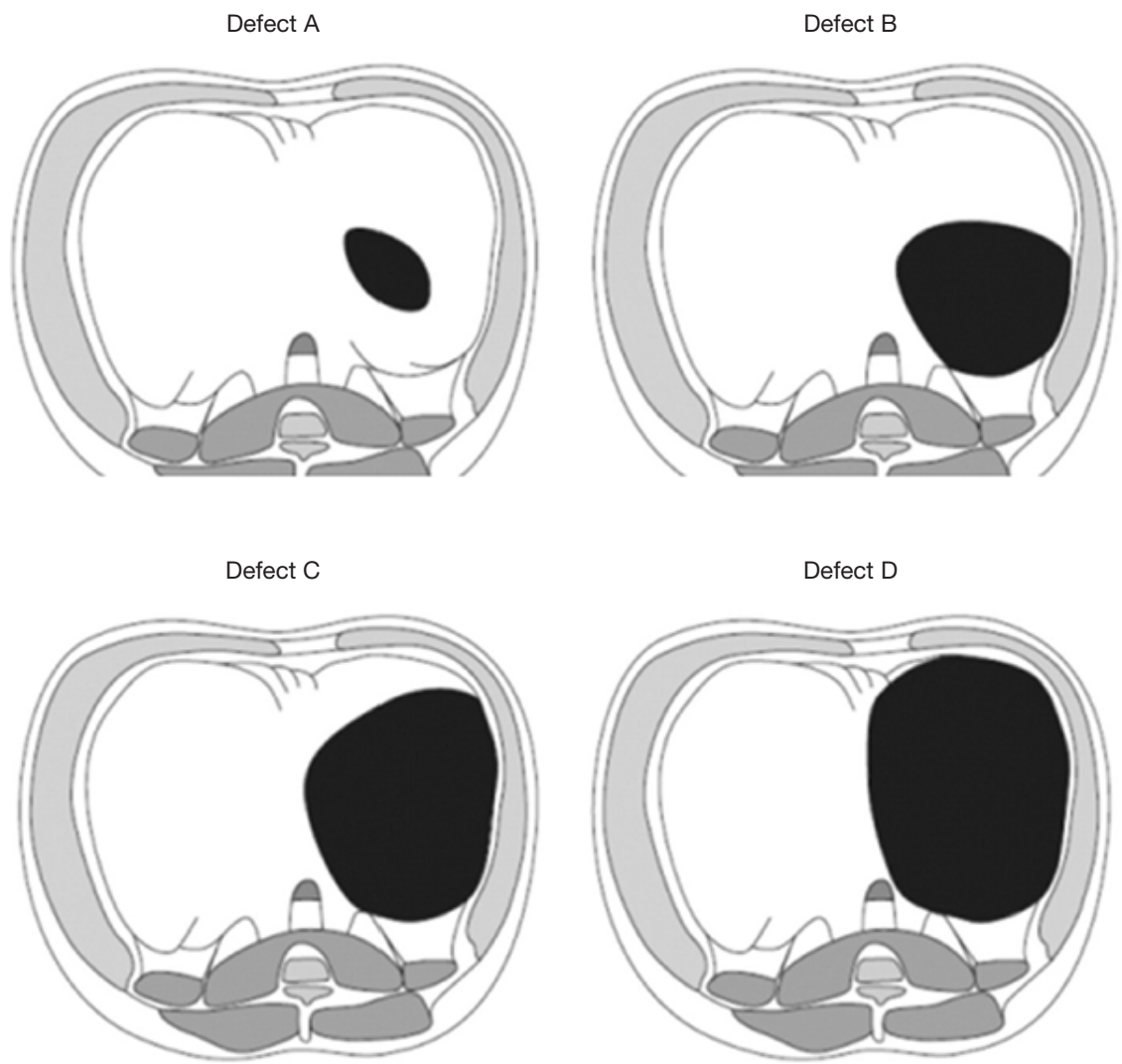

Figure 1 CDHSG staging system. This figure was published in fournal of Pediatric Surgery, Vol 48, Lally KP, Lasky RE, Lally PA et al., Standardized reporting for congenital diaphragmatic hernia--an international consensus, pages 2408-2415, Copyright Elsevier (2013) (2). Right to reproduce obtained by Elsevier.

in a neonatal intensive care unit (NICU) or pediatric intensive care unit (PICU). Given the complex medical and surgical nature of these infants, many collaboratives have sought to standardize management guidelines to decrease variation in care and improve overall outcomes (5-7). With few exceptions, such guidelines are almost entirely based on expert consensus driven recommendations. Few multicenter, randomized control trials exist to help guide the treatment of children with $\mathrm{CDH}$ and severe pulmonary hypertension. This review aims to discuss important and somewhat controversial aspects of neonatal management in these challenging children, mainly: the use of fraction of inspired oxygen, surfactant therapy, gentle ventilation, mode of ventilation, medical management of pulmonary hypertension (inhaled nitric oxide, sildenafil, milrinone, bosentan, prostaglandins), the utilization of extracorporeal membrane oxygenation, and the timing of surgical repair. We present the following article in accordance with the Narrative Review reporting checklist (available at http:// dx.doi.org/10.21037/tp-20-142).

This narrative review was compiled through study, analysis, and discussion of previously published journal articles specific to the treatment of congenital diaphragmatic hernia. An emphasis was placed on recent literature over the past 10 years, 2010-2020, however, older studies were included when necessary. Published material was identified utilizing the PubMed ${ }^{\circledR}$ (National Center for Biotechnology Information, United States National Library of Medicine, National Institutes of Health) database using multiple combinations of the keywords: congenital diaphragmatic hernia, $\mathrm{CDH}, \mathrm{ECMO}$, management, pulmonary hypertension, repair, surgery, and ventilation. The articles were then read for relevancy and the bibliographies reviewed for additional citations. Importance of the publications were based on previously described levels of evidence (8). Article inclusion within this review was determined by the authors after their evaluation, analysis and interpretation. 


\section{Fraction of inspired oxygen (FiO2)}

Historically, resuscitation of $\mathrm{CDH}$ neonates has been to start with an $\mathrm{FiO}_{2}$ of 1.0 (9-11). However, there is concern that oxygen itself increases the risk of oxidative stress and decreases the effectiveness of nitric oxide induced vasorelaxation (12-15). A review of $68 \mathrm{CDH}$ care guidelines from North American institutions noted that more than half of them (58\%) did not provide initial $\mathrm{FiO} 2$ recommendations (16). Currently, the revised 2016 EURO $\mathrm{CDH}$ Consortium recommends initiating resuscitation at an $\mathrm{FiO}_{2}$ of less than 1.0 (7). Recent literature is emerging that resuscitation with an $\mathrm{FiO}_{2}$ of less than 1.0 may be safe without worsening outcomes of survival, extracorporeal membrane oxygenation (ECMO) use or duration of mechanical ventilation $(17,18)$. Riley et al. compared a historical control group starting resuscitation at FiO2 of 1.0 to their study cohort that initiated resuscitation with $\mathrm{FiO}_{2}$ of 0.5 (17). They noted that $\mathrm{FiO}_{2}$ of 1.0 was associated with lower survival (69\% vs. $95 \%, \mathrm{P}=0.005)$, increased incidence of ECMO (38\% vs. $15 \%, \mathrm{P}=0.034)$, longer time to repair (24.5 vs. 14.2 days, $\mathrm{P}=0.023$ ) as well as higher incidence of periventricular leukomalacia $(18 \%$ vs. $0 \%, \mathrm{P}=0.01)$ and lower motor scores at 12 months (mean $75.8 \pm 18.1$ vs. $91.7 \pm 12, \mathrm{P}=0.0037$ ). Another study demonstrated similar outcomes, including increased survival to discharge and overall decreased use in ECMO when initiating resuscitation using an $\mathrm{FiO}_{2}$ of 0.4 compared to 1.0 (18). Interestingly, only $18 \%$ of those children that started at an $\mathrm{FiO}_{2}$ of 0.4 required an increase to 1.0. These studies suggest that it may be beneficial to initiate resuscitation with an overall lower $\mathrm{FiO}_{2}$ and raise as needed, versus starting at 1.0 and weaning as able. However, the data supporting this are lacking, therefore, it is more appropriate to target a pre-ductal $\mathrm{O}_{2}$ saturation level of $80-85 \%$ using the $\mathrm{FiO}_{2}$ as necessary to do so. If an $\mathrm{FiO}_{2}$ level of 1.0 is initiated, it should be weaned as able to maintain the appropriate level of oxygen support.

\section{Surfactant}

Animal studies suggested that surfactant deficiency may contribute to $\mathrm{CDH}$ pathophysiology with a decrease in lung compliance, decreased concentration of alveolar phospholipids (especially phosphatidylcholine), and higher lung concentrations of total DNA and glycogen $(19,20)$. Although a limited number of case reports observed possible benefit with surfactant therapy in CDH infants $(21,22)$, this was not supported in studies reviewing its use in $\mathrm{CDH}$ neonates using the CDH study group (CDHSG) registry $(23,24)$. Currently, routine surfactant administration is not recommended in children born with $\mathrm{CDH}(7)$.

\section{Gentle ventilation}

In the past, $\mathrm{CDH}$ was considered a surgical emergency (25). Early mortality rates were high, and often attributed to pulmonary hypertension (4). Historically, management strategies targeted hyperventilation (i.e., hypocarbia) with high respiratory rates and variable peak inspiratory pressures in an effort to promote pulmonary vascular relaxation (25). However, this method often resulted in iatrogenic barotrauma of the hypoplastic lungs leading to chronic lung disease (26). Upon review of $68 \mathrm{CDH}$ autopsy specimens, Sakurai and colleagues noted $91 \%$ of the cases had evidence of ventilator induced injury with diffuse alveolar injury in the setting of hyaline membrane deposition (27). They speculated that mechanical ventilation played a significant role in the mortality for the $\mathrm{CDH}$ cohort when using hyperventilation with higher inspiratory pressures, leading to overdistention of alveoli. In 1985, Wung et al. first described success using a less aggressive approach to mechanical ventilation in neonates with severe respiratory failure complicated by persistent fetal circulation (28). They focused on minimizing pressure/volume delivery and lung over-distention with tolerance for higher $\mathrm{PaCO}_{2}$ into the 50-60 torr range. This same group subsequently reported the use of this approach in a $\mathrm{CDH}$ cohort accompanied by decreased barotrauma, lower ECMO use and improved survival (29). Subsequently, this approach, commonly referred to as "gentle ventilation", was adopted and reported by other institutions associated with improved survival rates and decreased use of ECMO (9,22,30-33). Wilson and colleagues reviewed their experience, comparing their eras of hyperventilation to that of gentle ventilation, reporting improved survival from $44 \%$ to $69 \%(\mathrm{P}<0.007)(33)$. Kays et al. showed an improvement in survival from $15 \%$ in an era of hyperventilation, to $44 \%$ with the use of ECMO and hyperventilation, and even greater to $78 \%$ with the use of gentle ventilation and ECMO $(\mathrm{P}<0.001)(32)$. More recently, in a study that compared lower versus higher end-expiratory pressures in post-repair $\mathrm{CDH}$ neonates on conventional mechanical ventilation (CMV), Guevorkian and colleagues reported improved lung mechanics and perfusion with lower distending pressures, further supporting the benefits of minimizing pulmonary 
Table 1 Ventilatory recommendations per current available guidelines

\begin{tabular}{|c|c|c|c|}
\hline & CDH EURO Consortium (7) & APSA (6) & Canadian CDH Collaborative (5) \\
\hline Rescue mode & HFOV & HFOV & HFOV or HFJV \\
\hline \multirow[t]{2}{*}{ Ventilator settings } & $\mathrm{PIP}<25 \mathrm{cmH}_{2} \mathrm{O}$ & $\mathrm{PIP}<25 \mathrm{cmH}_{2} \mathrm{O}$ & NA \\
\hline & PEEP $3-5 \mathrm{cmH}_{2} \mathrm{O}$ & PEEP $3-5 \mathrm{cmH}_{2} \mathrm{O}$ & \\
\hline \multirow[t]{2}{*}{ HFOV settings } & NA & $\mathrm{P}_{\mathrm{aw}} 13-15 \mathrm{cmH}_{2} \mathrm{O}$ & NA \\
\hline & & $\Delta$ pressure $30-40 \mathrm{cmH}_{2} \mathrm{O}$ & \\
\hline \multirow[t]{2}{*}{ Goal $\mathrm{SpO}_{2}$} & Pre-ductal $80-95 \%$ & Pre-ductal >85\% & Pre-ductal $85-95 \%$ \\
\hline & Post-ductal $>70 \%$ & & \\
\hline \multirow[t]{2}{*}{ Weaning } & $\mathrm{FiO}_{2}$ if pre ductal $>95 \%$ & NA & $\mathrm{FiO}_{2}$ if pre ductal $>95 \%$ \\
\hline & PIP/PEEP if $\mathrm{PaCO}_{2}<50 \mathrm{mmHg}$ & & \\
\hline
\end{tabular}

ABG, arterial blood gas; APSA, American Pediatric Surgical Association; CMV, conventional mechanical ventilation; FiO $_{2}$, Fractional inspired oxygen; HFJV, high frequency jet ventilation; HFOV, high frequency oscillatory ventilation; $\mathrm{P}_{\text {aw }}$, mean airway pressure; PEEP, positive end expiratory pressure; PIP, peak inspiratory pressure.

overdistention in infants with relative lung hypoplasia (34). Currently, all published guidelines recommend preferential lower airway pressures while allowing for permissive hypercapnia (5-7,35). Table 1 summarizes the findings above. These systematic reviews support the use of gentle ventilation strategies to achieve improvements in survival while minimizing iatrogenic lung injury.

\section{Mode of ventilation}

Though it is now "standard of care" to use a gentle ventilation approach, optimal initial mode of ventilation for the $\mathrm{CDH}$ cohort has yet to be determined. Theoretically, the use of high frequency ventilation may allow for optimal gas exchange and minimization of ventilator induced lung injury via application of adequate distending pressure to optimize lung inflation and prevent atelectasis while using very low tidal volumes to minimize stretch-related "volutrauma" to the hypoplastic lungs (36). In Sakurai's review of CDH autopsy cases, in contrast to babies managed via $\mathrm{CMV}$, they noted very low rates of hyaline membrane formation in cases with early high frequency oscillatory ventilation (HFOV) use, supporting the possibility of lower ventilator induced lung injury with high frequency ventilation. There are several retrospective single-center reports describing success with $\mathrm{HFOV}$ as the initial ventilatory support mode in neonates with $\mathrm{CDH}(9,37-40)$. Reported starting frequencies ranged from $10-15 \mathrm{~Hz}$ with mean airway pressures (Paw) typically initiated at $13-15 \mathrm{cmH}_{2} \mathrm{O}$ range. The exception is the report by Reyes et al. who described an initial Paw range from $5-20 \mathrm{cmH}_{2} \mathrm{O}$, with more than $50 \%$ starting at less than $12 \mathrm{cmH}_{2} \mathrm{O}(41)$. The importance of not over-distending the hypoplastic lungs of the $\mathrm{CDH}$ infant was emphasized by the authors and discussants in all of the above cited studies.

One of the few randomized control trials performed in neonates with $\mathrm{CDH}$ is the multi-center VICI-trial, where investigators randomized $\mathrm{CDH}$ neonates to either $\mathrm{CMV}$ or HFOV (42). The trial was stopped after enrollment of 171 of a planned 200 participants in an inclusion period of 5 years because of lower than anticipated recruitment rates and limited financial resources. They observed no significant difference in the primary outcome of death or bronchopulmonary dysplasia between the two arms (CMV 45\% vs. HFOV 54\%, OR 0.62, 95\% CI: 0.25-1.55, $\mathrm{P}=0.31$ ). However, neonates randomized to $\mathrm{HFOV}$ were more frequently treated with iNO, vasoactive infusions, and ECMO. It is important to note that calculation of the initial Paw used in the CMV group was approximately $7-10 \mathrm{cmH}_{2} \mathrm{O}$, while the initial Paw in the HFOV group was 
Table 2 Comparison of HFOV settings and outcomes between Snoek et al. and Yang et al. related to starting mean airway pressure ( $\left.\mathrm{P}_{\text {aw }}\right)$

\begin{tabular}{|c|c|c|c|c|}
\hline & \multicolumn{2}{|c|}{ Snoek et al. (42) Study Group } & \multicolumn{2}{|c|}{ Yang et al. (18) $\mathrm{P}_{\mathrm{aw}}$ Era } \\
\hline $\mathrm{P}_{\mathrm{aw}}$ on $\operatorname{HFOV}\left(\mathrm{cmH}_{2} \mathrm{O}\right)$ & $7-10$ & $13-17$ & $13-15$ & $10-12$ \\
\hline iNO & $43 \%$ & $56 \%$ & $81 \%$ & $44 \%$ \\
\hline Vasoactive medication use & $80 \%$ & $91 \%$ & $83 \%$ & $65 \%$ \\
\hline Survival & $69 \%$ & $77 \%$ & $74 \%$ & $89 \%$ \\
\hline
\end{tabular}

CMV, conventional mechanical ventilation; ECMO, extracorporeal membrane oxygenation; HFOV, high frequency oscillatory ventilation; iNO, inhaled nitric oxide; $\mathrm{P}_{\mathrm{aw}}$, mean airway pressure.

higher at $13-17 \mathrm{cmH}_{2} \mathrm{O}$. Though most experts recommend setting the Paw $2-3 \mathrm{cmH}_{2} \mathrm{O}$ higher when transitioning from $\mathrm{CMV}$ to HFOV, CDH infants in the VICI-trial averaged about 6-7 $\mathrm{cmH}_{2} \mathrm{O}$ higher in the HFOV group. Although the authors concluded that there was no difference between CMV or HFOV as the primary mode of ventilation, based on their primary outcome, many institutions and guidelines recommend initiating respiratory support with CMV because of the increased rates for iNO, inotrope infusions, and ECMO in the HFOV study group (42). However, the large difference in airway pressures make it challenging to draw comparative conclusions between the two groups, as the much higher Paw in the HFOV group could contribute to relative lung over-inflation in the hypoplastic lungs of these $\mathrm{CDH}$ neonates. In that context, we recently reported the effect associated with a change in our approach to $\mathrm{CDH}$ management, including a lower initial Paw during HFOV support, our primary ventilatory mode for $\mathrm{CDH}$ (18). We found a significant decrease in the use of $\mathrm{iNO}$, inotropes and $\mathrm{ECMO}$ in the cohort of $\mathrm{CDH}$ neonates primarily managed with HFOV initiated at a significantly lower Paw \{median 11 [10-12] vs. 13 [12-15] $\mathrm{cmH}_{2} \mathrm{O}$ \} (18). This comparison is summarized in Table 2.

In the context of fragile, hypoplastic lungs, high frequency jet ventilation (HFJV) may have theoretical and clinical advantages over HFOV. Both in vitro and in vivo studies suggest that HFJV can be used to support gas exchange at Paw comparable to or lower than CMV, and with less adverse effect on cardiopulmonary hemodynamics than either CMV or HFOV (43-47). One of the earliest reports to describe HFJV in neonates with $\mathrm{CDH}$ was by Boros et al. who reported improvement in arterial blood gas measures with HFJV as a "rescue" mode (43). Subsequently, Kuluz et al. reported using HFJV to rescue $16 \mathrm{CDH}$ neonates with respiratory failure on CMV, though they did not find significant survival benefit in their small cohort (48). More recently, Attar et al. reviewed their experience using high frequency ventilation as a rescue modality with 22 $\mathrm{CDH}$ neonates managed on HFJV and 17 on HFOV ( $\mathrm{n}=44)$. They observed an improvement in ventilation with high frequency rescue in general $(\mathrm{P}=0.001)$ and a significant decrease in $\mathrm{PaCO} 2$ for the HFJV cohort $(\mathrm{P}<0.001)$. In this small series they found no improvement in oxygenation, but Paw was significantly increased in the HFOV managed infants compared to those on HFJV support. They suggest that HFJV may be a superior ventilatory modality for optimizing ventilation with lower Paw compared to HFOV for rescue of $\mathrm{CDH}$ neonates but note that prospective studies are needed to better define the optimal mode and approach (49). Current published guidelines recommend the use of high frequency ventilation (HFOV or HFJV) as a possible rescue mode at this time although several studies mentioned above demonstrate the value of this modality as the initial ventilatory management.

\section{Management of pulmonary hypertension}

Pulmonary hypertension is a significant cause of morbidity in children with $\mathrm{CDH}$. It arises from abnormal pulmonary vasculature development due to increased arterial remodeling, decreased vascular bed density and altered vascular responsiveness $(50,51)$. Autopsy specimens of $\mathrm{CDH}$ neonates show more abundant, mature contractile smooth muscle cells in the adventitial and medial layers of the pulmonary vasculature (52). In a rabbit $\mathrm{CDH}$ model, Schmidt et al. noted increased phenylephrine induced contractions of the left pulmonary artery with decreased relaxation compared to the aorta (53). Many 
different pathways have been implied in the underlying pathophysiology, with treatments specifically targeting these pathways, such as inhaled nitric oxide (iNO), sildenafil, milrinone, bosentan, and prostaglandins. Each will be discussed below.

\section{iNO}

The nitric oxide pathway is an important contributor to postnatal pulmonary vascular relaxation. Nitric oxide synthase (NOS) present in the endothelium catalyzes the production of nitric oxide (NO), allowing for NO diffusion to vascular smooth muscle cells where it promotes vasodilation via a guanylyl cyclase induced cyclic GMP (cGMP) mediated pathway. In both animal models and human postmortem lungs, varying reports of either underexpression (54-56) or over-expression of endothelial nitric oxide synthase (eNOS) has been reported $(57,58)$. Solari and colleagues observed a significant decrease in eNOS expression from pulmonary hypertension complicated deceased $\mathrm{CDH}$ neonates (56). Mous et al. showed an increase in eNOS expression and theorized that this may be secondary to decreased NO availability or by increased eNOS uncoupling which leads to increased oxidative stress (57). Recently, Nakamura and colleagues provided data suggesting decreased production of nitric oxide synthase interactive protein (NOSIP) in pulmonary vascular smooth muscle cells, which normally reduces endogenous NO production by interactions with eNOS (59). They suggest that NOSIP may contribute to increased eNOS and NO production, which in turn would lead to desensitization of downstream guanylyl cyclase and ultimately vasoconstriction.

Given this disturbed physiology, iNO was thought to be a promising therapy for $\mathrm{CDH}$ related pulmonary hypertension. Early case reports described temporary benefits in oxygenation for some $\mathrm{CDH}$ patients $(60,61)$. However, a large multi-center, randomized control trial (NINOS-trial) conducted in 1997 concluded no difference in the combined outcome of survival or need for ECMO with the use of iNO in $\mathrm{CDH}$ infants, though the trial was stopped early given lack of efficacy (62). Limitations of the NINOS-trial included enrollment during a different respiratory management era which was prior to the standard of the gentle ventilation method. Also, iNO was administered as a late rescue modality rather than as early treatment of pulmonary hypertension. Review of the prospective CDHSG database noted variable practice in the use of iNO amongst enrolling institutions (63). These investigators reported an association between the trend of iNO use and mortality, with a $15 \%$ higher absolute mortality rate (95\% CI: 0.1-0.2). Despite this, recent reports suggest that there may be subgroups of $\mathrm{CDH}$ neonates who respond to iNO therapy $(64,65)$. For example, older $\mathrm{CDH}$ neonates with late pulmonary hypertension on minimal respiratory support benefited from iNO when administered through non-invasive measures such as nasal cannula (65). Herich et al. noted that of $265 \mathrm{CDH}$ neonates, approximately $31 \%$ responded within 1 hour of iNO administration with an increase in $\mathrm{PaO}_{2}$ of $10-20 \%$ and a decrease in oxygenation index by greater than 5 points $(\mathrm{P}<0.0001)$ (64). Additionally, ECMO utilization $(67 \% v s$. $48 \%, \mathrm{P}=0.0024)$, and mortality ( $17 \%$ vs. $29 \%, \mathrm{P}=0.04)$ were both decreased compared to non-iNO responders. Finally, a retrospective study of a single institution with $73 \%$ of $\mathrm{CDH}$ neonates treated with iNO for severe pulmonary hypertension reported a $40 \%$ response rate in those with preserved left ventricular systolic function (66). Response was defined by improvements in $\mathrm{PaO}_{2}$ levels of greater than $20 \mathrm{mmHg}$ and subsequent improvements in alveolararterial gradients and $\mathrm{PaO}_{2} / \mathrm{FiO}_{2}$ ratios (both $\mathrm{P}<0.01$ ). In contrast to non-responders, they reported a decreased need for $\mathrm{ECMO}(24 \%$ vs. $50 \%, \mathrm{P}=0.02)$. These investigators concluded that iNO treatment may be beneficial in a subset of $\mathrm{CDH}$ neonates with normal left ventricular systolic function and pulmonary hypertension (66). As iNO use can lead to increased pulmonary venous return, this might precipitate cardiopulmonary failure in a left ventricle that is compromised in size and/or function. Given the transient nature of response to iNO, its utility may actually be significantly limited in even these infants. In summary, a trial of iNO for severe pulmonary hypertension may be reasonable, however, cessation should occur if a response is not observed within 24 hours, as is currently the recommendation of various practice guidelines $(5-7)$.

\section{Sildenafil}

Along the NO pathway, cGMP is hydrolyzed and inactivated by the enzyme phosphodiesterase-5 (PDE-5). One method to enhance the effect of endogenous or supplemented NO would be to target cGMP catabolism. There is concern that PDE-5 is abnormally upregulated in the $\mathrm{CDH}$ cohort (67). Vukcevic et al. hypothesized that the decreased postnatal response to nitric oxide for $\mathrm{CDH}$ is due to altered postnatal PDE-5 activity. They tested this theory by inhibiting PDE-5 activity in postnatal nitrofen-induced 
$\mathrm{CDH}$ rat pulmonary arterioles. Following sildenafil citrate exposure, they observed an increased vasodilatory response to cGMP, similar to that seen with the control arterioles (67). Thus, the use of PDE-5 inhibitors such as sildenafil citrate, may be beneficial for $\mathrm{CDH}$ related pulmonary hypertension.

Case reports exist detailing the use of sildenafil for $\mathrm{CDH}$ related pulmonary hypertension with improvement in oxygenation $(68,69)$. Noori et al. reviewed $7 \mathrm{CDH}$ patients with pulmonary hypertension noting improvement in cardiac output due to acute decrease in pulmonary arterial pressures within 1-4 hours after administration of sildenafil, with improvement in oxygenation (69). Similar improvement in oxygenation with improvement in echocardiographic markers of pulmonary hypertension was noted with IV sildenafil administration in $9 \mathrm{CDH}$ cases (68). None of the reports to date include untreated/control patients and there is concern for increased vasopressor support with the use of IV sildenafil secondary to systemic hypotension, especially during the first hours of therapy (70), thus, some caution is warranted. Currently, a multi-center, randomized control trial is ongoing in Europe comparing iNO to IV sildenafil therapy (NTR6982) (71). In theory, combined use of these agents may be most effective at lowering pulmonary vascular resistance (72). These studies suggest that earlier administration of sildenafil may be most effective, however, the benefit of this effect remains unclear due to limited data and lack of randomized trials.

\section{Milrinone}

Milrinone is a selective phosphodiesterase-3 (PDE-3) inhibitor that prevents the breakdown of cAMP, resulting in increased cardiac contractility, relaxation and vasodilation. Given these properties, it is commonly used in the pediatric population for low cardiac output syndrome (73). It has also been used for persistent pulmonary hypertension of the newborn $(74,75)$ with a pilot, randomized control trial studying the use of milrinone with iNO currently in the process of enrolling participants (ISRCTN 12949496;EudraCT 2014-002988-16) (76). In the CDH cohort, the first study reported on milrinone used as adjunct therapy to other vasodilators in six patients with pulmonary hypertension and right heart dysfunction (77). They reported a decrease in oxygenation index and improvement in diastolic function, as well as a trend towards improving right ventricular systolic function. The author saw no changes to pulmonary nor systemic pressures (77). Kumar et al. reviewed $12 \mathrm{CDH}$ neonates managed with milrinone and iNO and also reported improvements in oxygenation index and left ventricular ejection fraction compared to premilrinone measures (78). Unfortunately, neither of these reports included a control study group. Subsequently, Mears and colleagues reported a retrospective study analyzing $48 \mathrm{CDH}$ neonates matched by oxygenation index, 24 of whom were treated with milrinone (79). Both groups showed similar rates of improvement in oxygenation index, ductal shunt and left ventricular size over time, with no measurable changes in calculated pulmonary artery pressure. There was no difference in oxygenation index, pulmonary arterial pressure nor echocardiographic measures of left ventricular size over time between the milrinone treated versus untreated groups. Currently, a multi-center, placebo controlled, randomized control trial is ongoing to evaluate the use of milrinone in CDH (NCT02951130) (80). Thus, despite wide-spread use, data are limited into the usefulness of milrinone in $\mathrm{CDH}$. Hopefully, ongoing randomized trials will help clarify the role of milrinone in treatment of $\mathrm{CDH}$ associated pulmonary hypertension.

\section{Bosentan}

Another known regulator of pulmonary vascular tone is the endothelin system, including endothelin-1 (ET-1). ET-1 acts through two different receptors subtypes: vasoconstricting ET-A and the vasodilatory receptor subunit, ET-B (81). de Laguasie et al. provided one of the earliest reports studying $\mathrm{CDH}$ autopsy specimens using immunohistochemistry and real-time PCR with laser microdissection (81). They observed significant overexpression of ET-A and ET-B in CDH pulmonary arteries compared to controls. Mous et al. also found an increased expression of ET-A and B receptors in both the rat model and human $\mathrm{CDH}$ patients (57). Keller and colleagues noted significantly higher plasma ET-1 levels in their combined outcome of death or supplemental oxygen at time of discharge, compared to those who survived to hospital discharge on room air (82). Bosentan is a competitive inhibitor of ET-A and ET-B, with a higher affinity for ET-A. Theoretically, this could induce pulmonary vasodilation and work as a therapeutic modality for $\mathrm{CDH}$ related pulmonary hypertension. A randomized trial comparing the use of bosentan with placebo as treatment for neonates with persistent pulmonary hypertension (not from $\mathrm{CDH}$ ) noted a favorable response as defined by an oxygenation index less than 15, normal pulmonary 
arterial pressures and no premature discontinuation of the medication secondary to lack of efficacy or toxicity (83). Bosentan therapy was superior when compared to placebo ( $88 \%$ vs. $20 \%, \mathrm{P}<0.0001$ ). To our knowledge, there are no studies on bosentan in the $\mathrm{CDH}$ cohort.

\section{Prostacyclin}

Prostacyclin (PGI2) is an endogenous eicosanoid that has vasodilatory effects on the pulmonary vasculature via cyclic AMP mediated decreases in endothelial intracellular calcium (84). IV prostacyclin has a short half-life, requiring continuous infusion (85). Treprostinil is a prostacyclin analog which can be administered subcutaneously (86). There are only limited studies on the use of prostacyclin analogues in the $\mathrm{CDH}$ pulmonary hypertension population (84-87). A retrospective study with $52 \mathrm{CDH}$ neonates had a $46 \%$ incidence of pulmonary hypertension where either tolazoline or prostacyclin was administered (85). The group noted a significant decrease in both alveolar-arterial oxygen difference and oxygenation index without complications of systemic hypotension $(\mathrm{P}<0.05)(85)$. A case series reviewed $14 \mathrm{CDH}$ patients treated with subcutaneous treprostinil for late-onset, confirmed pulmonary hypertension by echocardiography who were unresponsive to iNO and sildenafil therapy (86). Improvement in oxygenation and increased pulmonary blood flow was noted with initiation of therapy, and patients tolerated the treatment well. Another small retrospective study reviewed $17 \mathrm{CDH}$ neonates who were treated with treprostinil for extreme pulmonary hypertension (88). A significant decrease in b-type natriuretic peptide (BNP) levels at 1 week and 1 month of treatment was observed and corresponded to echocardiographic improvement of severe pulmonary hypertension. Moreover, treprostinil was well tolerated without need for therapy discontinuation or dose reduction secondary to adverse events. Although promising, larger, multi-center, randomized controlled trials are needed to evaluate the safety and efficacy of prostacyclin use in neonates with $\mathrm{CDH}$ associated pulmonary hypertension.

\section{Prostaglandin}

With severe, uncontrolled pulmonary hypertension, mortality may be related to right ventricular failure. In the $\mathrm{CDH}$ cohort, the left ventricle is often underdeveloped due to decreased pulmonary blood flow, leading to decreased fetal preload (89). With severe CDH cases, systemic output could be more dependent on right ventricular function. Given this, the use of prostaglandin E1 (PGE1) to provide ductus arteriosus patency may allow for right ventricular pressure relief, leading to improved right ventricular function and allowing time for pulmonary vascular relaxation. Shiyanagi and colleagues reviewed 49 cases with $\mathrm{CDH}$ related pulmonary hypertension where 19 were managed with iNO and PGE1 and 30 neonates with iNO alone (90). They noted no difference in survival to discharge, however, a shorter duration of hospitalization and earlier dates of repair was observed for those on iNO alone. Lawrence et al. reviewed their experience using PGE1 for severe pulmonary hypertension with $\mathrm{CDH}$ $(n=57)(66)$. Although most of these patients were initiated on iNO (88\%), the addition of PGE1 had an improvement in pulmonary hypertension evidenced by a significant reduction in BNP biomarker levels and echocardiographic evidence of decreased supra-systemic right ventricular pressures. Unfortunately, no prospective studies have been conducted to date comparing the use of PGE1 alone or in combination with other therapies targeting pulmonary hypertension in neonates with $\mathrm{CDH}$. All studied therapies for pulmonary hypertension reviewed above are summarized in Table 3.

\section{Extracorporeal membrane oxygenation (ECMO)}

When a newborn with $\mathrm{CDH}$ remains critically ill from pulmonary hypoplasia, the use of extracorporeal membrane oxygenation should be considered before severe lung injury has occurred. It is important that the utilization of ECMO be anticipated in these infants with early cannulation prior to levels of ventilator support that can permanently damage the fragile lung tissue. Approximately a third of babies with $\mathrm{CDH}$ are managed with ECMO therapy (91), however, its utilization across differing centers within North America is highly variable (16). Despite advancement in ECMO therapy, the survival rate of $\mathrm{CDH}$ infants rescued with ECMO has remained approximately $50 \%$ for the last 30 years (92). Although, it is likely that over this period of time, due to improvements in ventilation strategies, only the most severe cases now require ECMO therapy (91). We recently reported a decrease in overall ECMO utilization from $37 \%$ to $13 \%$ after a change in our $\mathrm{CDH}$ clinical practice guideline (18). However, this begs the question of whether the proper selection criteria are known to initiate ECMO rescue in infants with severe $\mathrm{CDH}$ associated pulmonary hypoplasia. More importantly, are there variables 
Table 3 Current available/proposed pulmonary vasodilator therapies and evidence for use in CDH

\begin{tabular}{lcccc}
\hline Therapy & Case series & Controls included & Randomized trials & Results \\
\hline iNO & Yes $(61,62,64,76)$ & Yes & Yes (62) & No benefit by RCT (+) with targeting by LV function \\
Sildenafil & Yes $(68,69)$ & No & No, on-going $(71)$ & Suggested benefit \\
Milrinone & Yes $(77,78)$ & Yes & No, on-going (80) & $(+)$ by case only, (-) with controls \\
Bosentan & No & No & No & Unknown \\
PGI & Yes $(85,86,88)$ & No & No & Suggested benefit \\
PGE & Yes $(66,90)$ & No & No & Suggested benefit \\
\hline
\end{tabular}

iNO, inhaled nitric oxide; PGI, prostacyclin; PGE, prostaglandin. Referenced articles in parenthesis.

that should be used to help decide which children will actually benefit from ECMO and which children will not? Currently, contraindications for ECMO support are based on weight $(<2 \mathrm{~kg})$, gestational age ( $<32$ weeks), presence of cardiac anomalies, lethal chromosomal anomalies, or occurrence of grade III/IV intraventricular hemorrhage (91). These contraindications were further confirmed using the Delphi approach with current and former members of the American Pediatric Surgical Association Critical Care Committee (93). However, this study by Cairo et al. also reported a significant variation in responses of whether or not the $\mathrm{CDH}$ should be repair in a child who required ECMO support for $4-5$ weeks. The bigger question is whether such children should have been placed on ECMO to begin with? Recently, the Michigan group has presented their yet to be published study of their Severe Pulmonary Hypoplasia and Evaluation for Resuscitation Efforts (SPHERE) protocol to help guide ECMO utilization in the most severe CDH neonates (liver up, LHR $<1$, MRI O/E TFLV $<25 \%)$. ECMO was initiated only if the infant could obtain a $\mathrm{pH}>7.0, \mathrm{pCO}_{2} \leq 100$, preductal $\mathrm{SpO}_{2}>80 \%$ and $\mathrm{PCO} 2 \geq 40$ on gentle ventilation settings for the first 2 hours of life (94). Of the 23 patients with severe CDH included in their initial single institutional retrospective study, $57 \%$ fit criteria for ECMO, with the remainder receiving comfort care only. Patient survival was $46 \%$ with longterm gastrointestinal, pulmonary, and neurodevelopment sequelae seen in all. When the same criteria were applied to the CDHSG database, no significant difference in survival was seen between patients that would have passed and those that would have failed the SPHERE protocol (53.7\% vs. $47.4 \%, \mathrm{P}=0.47)$, however, those that would have failed experienced a significantly longer course on ECMO (11 vs. 14 days, $\mathrm{P}=0.03)$ and were more likely to still be on ECMO or a ventilator at 30 days $(95.8 \%$ vs. $69.1 \%, \mathrm{P}=0.006)(95)$.
Amongst the survivors, those that would have failed the SPHERE protocol were more likely to still be on a ventilator or $\mathrm{ECMO}$ at 30 days $(94.1 \%$ vs. $59.6 \%, \mathrm{P}=0.006)$, had a longer overall hospital length of stay (108 vs. 81.5 days, $\mathrm{P}=0.008$ ), and required supplemental feedings (94.4\% vs. 69.2\%, $\mathrm{P}=0.02$ ). Although when retrospectively reviewed in a larger dataset no difference in survival was identified, criteria like this are worth studying further, especially to look at long-term mortality in those children who would have failed the SPHERE protocol as this was probably not captured once the child was discharged from the hospital.

The mode of ECMO, venoartarial (VA) or venovenous (VV), is a subject of debate and often falls along the line of institutional bias. Several retrospective, single institutional studies have reported that overall survival is equivalent between VV and VA ECMO support (96-99). More recent data using the Extracorporeal Life Support Organization (ELSO) database confirmed no significant difference in the odds of death (OR 1.01, 95\% CI: 0.86-1.18, P=0.95) between propensity matched cohorts of $\mathrm{CDH}$ infants having undergone VV or VA ECMO (100). In a subgroup analysis of infants with pre-ECMO $\mathrm{CDH}$ repair, $\mathrm{VV}$ was found to have higher mortality (OR 2.10, 95\% CI: 1.19-3.69, $\mathrm{P}=0.10)$ with no difference in significant neurologic injury (OR 1.48, 95\% CI: 0.59-3.71, $\mathrm{P}=0.399$ ) when compared to VA. In another subgroup analysis of infants who did not have pre-ECMO CDH repair, VV ECMO was associated with a lower incidence of a significant neurologic injury (OR 0.73, 95\% CI: 0.56-0.95, $\mathrm{P}=0.021)$. There is an approximate conversion rate from $\mathrm{VV}$ to VA ECMO of $15 \%$ when support is not adequate with an associated higher mortality rate $(63.2 \%)$ compared to VA (52.6\%) and VV (48.0\%) alone (100). It should be noted that no prenatal stratification was provided in any of 
these studies, such as liver location or lung measurements, therefore, it is hard to quantify the overall severity of disease in the included patients. Therefore, there may be benefit in using the VV approach in infants who are placed on ECMO prior to $\mathrm{CDH}$ repair and the VA approach in only the most severe cases treated with ECMO.

There is no doubt that ECMO serves as an important adjunct in the treatment of the severest of $\mathrm{CDH}$ babies, although its rate of use has decreased due to improvement in the overall medical management of these children $(18,101)$. However, the degree to which ECMO improves survival is difficult to determine given the lack of large multi-institutional randomized trials, the wide variation of care between institutions, and overall limitations of the reported literature $(92,101)$. Additionally, not all studies may actually account for late-term mortality, or death that occurs greater than 90 days after ECMO, making the survival benefit seem higher than it really is (102). It is also important to remember that the use of ECMO alone is an independent predictor of long-term neurodevelopmental delay (103) and long-term follow-up and care is required to recognize ECMO-related impairments in order to intervene early (102).

\section{Timing of surgical repair}

With improvement of the overall medical management, the timing of repair remains controversial without any definitive study that demonstrates superiority of early (within 24 hours) or delayed repair (104). In infants with mild pulmonary hypertension, the decision is less challenging, and timing usually varies from institution to institution. In general, a period of neonatal transition is followed by repair as soon as the infant is deemed physiologically stable for surgery by the neonatology and surgical teams. This can be fairly subjective and no objective way of determining proper timing has been published to date, although, it appears that the timing of repair in low-risk children does not have an effect on overall outcomes (105).

For infants with more severe pulmonary hypertension, multiple strategies for repair exist. Sakai et al. demonstrated that physiologic deterioration occurs following $\mathrm{CDH}$ repair making timing crucial in these children (4). Several studies have demonstrated the benefits of repairing the defect early on ECMO (106-109). In review of the CDHSG database, Glenn et al. identified 248 children who were repaired within 72 hours of cannulation and compared them to 922 who remained unrepaired (109). Though the early repair group had significantly less intraabdominal liver (10.9\% vs. $11.6 \%, \mathrm{P}=0.001)$ and were less likely to have the presence of a hernia sac $(5.2 \%$ vs. $10.9 \%, \mathrm{P}=0.009)$, they had improved survival to ECMO decannulation (87.1\% vs. $78.4 \%, \mathrm{P}=0.002)$.The early repair group, however, $\mathrm{did}$ have a significantly longer median time on ECMO than the unrepaired group (240.6 vs. 196.8 hours, $\mathrm{P}=0.001$ ). In a single retrospective review, Fallon et al. demonstrated improved survival in those children repaired early in the course of ECMO versus those late in the course $(73 \%$ vs. $50 \%, \mathrm{P}=0.27)$. This did not reach statistical significance, most likely due to the small numbers of the cohort. Contrary to the study reported by Glenn et al., their study demonstrated a decrease in overall ECMO duration in those children repaired early (12 vs. 18 days, $\mathrm{P}=0.01$ ). Another recent study concluded that survival was improved if babies were repaired on ECMO compared to after ECMO and also that early repair on ECMO was superior to late repair (110). Dao et al. performed a retrospective study of the CDHSG database using propensity score matching to evaluate 2 individual aims: (I) compare repair on versus after ECMO and (II) compare early versus late repair on ECMO. A total of 1,423 patients were available for analysis spanning a 10-year period. Following propensity score matching, 136 patients were analyzed in each arm of aim $1(n=272)$. The analysis showed that those repaired on ECMO had an overall lower mortality with a hazard ratio of 0.54 (CI: $0.38,0.77, \mathrm{P}<0.001$ ) and odds ratio of 0.52 (CI: 0.32, 0.85, $\mathrm{P}=0.01$ ). Additionally, they were more likely to undergo repair $(94.1 \%$ vs. $66.2 \%, \mathrm{P}<0.001)$. In their analysis of aim 2 , a total of 154 patients were available for analysis following propensity score matching, 77 per arm. Those infants repaired early demonstrated an overall lower mortality rate with a hazard ratio of 0.51 (CI: $0.33,0.77, \mathrm{P}=0.002)$ and odds ratio of 0.19 (CI: $0.09,0.39, \mathrm{P}<0.001)$. Again, more were able to be repaired $(90.9 \%$ vs. $55.8 \%, \mathrm{P}<0.001)$ with an overall lower duration of ECMO support (median 13 days vs. 15 days, $\mathrm{P}=0.02$ ) and overall hospitalization in survivors (median 54 days vs. 95 days, $\mathrm{P}=0.004$ ). They concluded that early repair may be key to higher repair rates and improved mortality at higher volume centers.

Other smaller studies have demonstrated the benefit of repair after decannulation $(111,112)$. Partridge et al. compared patients repaired prior to cannulation $(n=3)$, during ECMO $(n=41)$, and after cannulation $(n=17)$ with those repaired after cannulation having a significantly improved survival (67\% vs. $43.9 \%$ vs. $100 \%$ respectively, $\mathrm{P}<0.001)$. They also reported that operative bleeding 
requiring transfusion occurred significantly more in the group repaired on ECMO compared to those repaired before and after cannulation $(29 \%$ vs. $0 \%$ vs. $0 \%, \mathrm{P}<0.01)$. More recently, using the ELSO registry, Delapain et al. used propensity scores to match infants based on pre-ECMO comorbidity variables then compared those that underwent repair on $\operatorname{ECMO}(n=1,112)$ to those that underwent repair after completion of ECMO $(n=1,112)(111)$. They demonstrated that the mortality of those repaired on ECMO was 3 times higher than those that underwent repair after decannulation (OR 3.41, 95\% CI: 2.84-4.09, $\mathrm{P}<0.01$ ). Additionally, they initially showed an increase in significant neurologic injury in the on ECMO repair group, however, this difference did not maintain significance when an additional sensitivity analysis was performed that included duration of ECMO. Finally, a single-center reviewed 87 children with left-sided $\mathrm{CDH}$, liver up, without associated anomalies, to assess the risk of ECMO as well as to evaluate timing of surgical repair (113). They reported that those children that underwent repair within 60 hours of life and before ECMO cannulation ( $\mathrm{n}=22)$ had a higher survival rate than those that underwent ECMO cannulation first $(n=20)$ (95.5\% vs. $65.0 \%, \mathrm{P}=0.018$ ). However, these outcomes reported are contrary compared to other large registry data previously described. One can see that the literature is not overwhelmingly clear and therefore, ultimately, the decision is typically dependent on both surgeon and institutional discretion.

The care of neonates with $\mathrm{CDH}$ remains challenging with a wide variation of care across institutions. This is further highlighted by a recent study demonstrating a lack of $\mathrm{CDH}$ clinical practice guidelines at over $1 / 4$ of surveyed centers (16). Although the literature is replete with studies evaluating treatment strategies, no large, multi-institutional studies exist to help determine best practice. Development of multi-institutional treatment guidelines with prospective data collection and review may be the only way to truly answer many of these controversial questions.

\section{Acknowledgments}

Funding: None.

\section{Footnote}

Provenance and Peer Review: This article was commissioned by the Guest Editors (Eric B. Jelin and George B. Mychaliska) for the series "Fetal Surgery" published in
Translational Pediatrics. The article has undergone external peer review.

Reporting Checklist: The authors have completed the Narrative Review reporting checklist. Available at http:// dx.doi.org/10.21037/tp-20-142

Peer Review File: Available at http://dx.doi.org/10.21037/tp20-142

Conflicts of Interest: All authors have completed the ICMJE uniform disclosure form (available at http://dx.doi. org/10.21037/tp-20-142). The series "Fetal Surgery" was commissioned by the editorial office without any funding or sponsorship. The authors have no other conflicts of interest to declare.

Ethical Statement: The authors are accountable for all aspects of the work in ensuring that any questions related to the accuracy or integrity of any part of the work are appropriately investigated and resolved.

Open Access Statement: This is an Open Access article distributed in accordance with the Creative Commons Attribution-NonCommercial-NoDerivs 4.0 International License (CC BY-NC-ND 4.0), which permits the noncommercial replication and distribution of the article with the strict proviso that no changes or edits are made and the original work is properly cited (including links to both the formal publication through the relevant DOI and the license). See: https://creativecommons.org/licenses/by-nc-nd/4.0/.

\section{References}

1. McHoney M. Congenital diaphragmatic hernia. Early Hum Dev 2014;90:941-6.

2. Lally KP, Lasky RE, Lally PA, et al. Standardized reporting for congenital diaphragmatic hernia--an international consensus. J Pediatr Surg 2013;48:2408-15.

3. Congenital Diaphragmatic Hernia Study Group; Morini F, Valfre L, et al. Congenital diaphragmatic hernia: defect size correlates with developmental defect. J Pediatr Surg 2013;48:1177-82.

4. Sakai H, Tamura M, Hosokawa Y, et al. Effect of surgical repair on respiratory mechanics in congenital diaphragmatic hernia. J Pediatr 1987;111:432-8.

5. Canadian Congenital Diaphragmatic Hernia Collaborative; Puligandla PS, Skarsgard ED, et al. Diagnosis and 
management of congenital diaphragmatic hernia: a clinical practice guideline. CMAJ 2018;190:E103-E12.

6. Puligandla PS, Grabowski J, Austin M, et al. Management of congenital diaphragmatic hernia: A systematic review from the APSA outcomes and evidence based practice committee. J Pediatr Surg 2015;50:1958-70.

7. Snoek KG, Reiss IK, Greenough A, et al. Standardized Postnatal Management of Infants with Congenital Diaphragmatic Hernia in Europe: The CDH EURO Consortium Consensus - 2015 Update. Neonatology 2016;110:66-74.

8. Burns PB, Rohrich RJ, Chung KC. The levels of evidence and their role in evidence-based medicine. Plast Reconstr Surg 2011;128:305-10.

9. Datin-Dorriere V, Walter-Nicolet E, Rousseau V, et al. Experience in the management of eighty-two newborns with congenital diaphragmatic hernia treated with highfrequency oscillatory ventilation and delayed surgery without the use of extracorporeal membrane oxygenation. J Intensive Care Med 2008;23:128-35.

10. Guidry CA, Hranjec T, Rodgers BM, et al. Permissive hypercapnia in the management of congenital diaphragmatic hernia: our institutional experience. J Am Coll Surg 2012;214:640-5, 7 e1; discussion 646-7.

11. Reiss I, Schaible T, van den Hout L, et al. Standardized postnatal management of infants with congenital diaphragmatic hernia in Europe: the CDH EURO Consortium consensus. Neonatology 2010;98:354-64.

12. Farrow KN, Lakshminrusimha S, Czech L, et al. SOD and inhaled nitric oxide normalize phosphodiesterase 5 expression and activity in neonatal lambs with persistent pulmonary hypertension. Am J Physiol Lung Cell Mol Physiol 2010;299:L109-16.

13. Ozsurekci Y, Aykac K. Oxidative Stress Related Diseases in Newborns. Oxid Med Cell Longev 2016;2016:2768365.

14. Tataranno ML, Oei JL, Perrone S, et al. Resuscitating preterm infants with $100 \%$ oxygen is associated with higher oxidative stress than room air. Acta Paediatr 2015;104:759-65.

15. Vento M, Asensi M, Sastre J, et al. Resuscitation with room air instead of $100 \%$ oxygen prevents oxidative stress in moderately asphyxiated term neonates. Pediatrics 2001;107:642-7.

16. Jancelewicz T, Brindle ME, Guner YS, et al. Toward Standardized Management of Congenital Diaphragmatic Hernia: An Analysis of Practice Guidelines. J Surg Res 2019;243:229-35.

17. Riley JS, Antiel RM, Rintoul NE, et al. Reduced oxygen concentration for the resuscitation of infants with congenital diaphragmatic hernia. J Perinatol 2018;38:834-43.

18. Yang MJ, Fenton S, Russell K, et al. Left-sided congenital diaphragmatic hernia: can we improve survival while decreasing ECMO? J Perinatol 2020;40:935-42.

19. Glick PL, Stannard VA, Leach CL, et al. Pathophysiology of congenital diaphragmatic hernia II: the fetal lamb $\mathrm{CDH}$ model is surfactant deficient. J Pediatr Surg 1992;27:3827; discussion 387-8.

20. Suen HC, Catlin EA, Ryan DP, et al. Biochemical immaturity of lungs in congenital diaphragmatic hernia. J Pediatr Surg 1993;28:471-5; discussion 476-7.

21. Bae CW, Jang CK, Chung SJ, et al. Exogenous pulmonary surfactant replacement therapy in a neonate with pulmonary hypoplasia accompanying congenital diaphragmatic hernia--a case report. J Korean Med Sci 1996;11:265-70.

22. Finer NN, Tierney A, Etches PC, et al. Congenital diaphragmatic hernia: developing a protocolized approach. J Pediatr Surg 1998;33:1331-7.

23. Van Meurs K, Congenital Diaphragmatic Hernia Study $\mathrm{G}$. Is surfactant therapy beneficial in the treatment of the term newborn infant with congenital diaphragmatic hernia? J Pediatr 2004;145:312-6.

24. Lally KP, Lally PA, Langham MR, et al. Surfactant does not improve survival rate in preterm infants with congenital diaphragmatic hernia. J Pediatr Surg 2004;39:829-33.

25. Sawyer SF, Falterman KW, Goldsmith JP, et al. Improving survival in the treatment of congenital diaphragmatic hernia. Ann Thorac Surg 1986;41:75-8.

26. Bohn D, Tamura M, Perrin D, et al. Ventilatory predictors of pulmonary hypoplasia in congenital diaphragmatic hernia, confirmed by morphologic assessment. J Pediatr 1987;111:423-31.

27. Sakurai Y, Azarow K, Cutz E, et al. Pulmonary barotrauma in congenital diaphragmatic hernia: a clinicopathological correlation. J Pediatr Surg 1999;34:1813-7.

28. Wung JT, James LS, Kilchevsky E, et al. Management of infants with severe respiratory failure and persistence of the fetal circulation, without hyperventilation. Pediatrics 1985;76:488-94.

29. Wung JT, Sahni R, Moffitt ST, et al. Congenital diaphragmatic hernia: survival treated with very delayed surgery, spontaneous respiration, and no chest tube. J Pediatr Surg 1995;30:406-9.

30. Bagolan P, Casaccia G, Crescenzi F, et al. Impact of 
a current treatment protocol on outcome of highrisk congenital diaphragmatic hernia. J Pediatr Surg 2004;39:313-8; discussion 318.

31. Boloker J, Bateman DA, Wung JT, et al. Congenital diaphragmatic hernia in 120 infants treated consecutively with permissive hypercapnea/spontaneous respiration/ elective repair. J Pediatr Surg 2002;37:357-66.

32. Kays DW, Langham MR, Jr., Ledbetter DJ, et al. Detrimental effects of standard medical therapy in congenital diaphragmatic hernia. Ann Surg 1999;230:3408; discussion 348-51.

33. Wilson JM, Lund DP, Lillehei CW, et al. Congenital diaphragmatic hernia--a tale of two cities: the Boston experience. J Pediatr Surg 1997;32:401-5.

34. Guevorkian D, Mur S, Cavatorta E, et al. Lower Distending Pressure Improves Respiratory Mechanics in Congenital Diaphragmatic Hernia Complicated by Persistent Pulmonary Hypertension. J Pediatr 2018;200:38-43.

35. Logan JW, Rice HE, Goldberg RN, et al. Congenital diaphragmatic hernia: a systematic review and summary of best-evidence practice strategies. J Perinatol 2007;27:535-49.

36. Gattinoni L, Quintel M, Marini JJ. Volutrauma and atelectrauma: which is worse? Crit Care 2018;22:264.

37. Cacciari A, Ruggeri G, Mordenti M, et al. High-frequency oscillatory ventilation versus conventional mechanical ventilation in congenital diaphragmatic hernia. Eur J Pediatr Surg 2001;11:3-7.

38. Desfrere L, Jarreau PH, Dommergues M, et al. Impact of delayed repair and elective high-frequency oscillatory ventilation on survival of antenatally diagnosed congenital diaphragmatic hernia: first application of these strategies in the more "severe" subgroup of antenatally diagnosed newborns. Intensive Care Med 2000;26:934-41.

39. Migliazza L, Bellan C, Alberti D, et al. Retrospective study of 111 cases of congenital diaphragmatic hernia treated with early high-frequency oscillatory ventilation and presurgical stabilization. J Pediatr Surg 2007;42:1526-32.

40. Miguet D, Claris O, Lapillonne A, et al. Preoperative stabilization using high-frequency oscillatory ventilation in the management of congenital diaphragmatic hernia. Crit Care Med 1994;22:S77-82.

41. Reyes C, Chang LK, Waffarn F, et al. Delayed repair of congenital diaphragmatic hernia with early high-frequency oscillatory ventilation during preoperative stabilization. J Pediatr Surg 1998;33:1010-4; discussion 1014-6.

42. Snoek KG, Capolupo I, van Rosmalen J, et al. Conventional Mechanical Ventilation Versus High- frequency Oscillatory Ventilation for Congenital Diaphragmatic Hernia: A Randomized Clinical Trial (The VICI-trial). Ann Surg 2016;263:867-74.

43. Boros SJ, Mammel MC, Coleman JM, et al. Neonatal high-frequency jet ventilation: four years' experience. Pediatrics 1985;75:657-63.

44. Kawahito S, Kitahata H, Tanaka K, et al. Transesophageal echocardiographic assessment of pulmonary arterial and venous flow during high-frequency jet ventilation. J Clin Anesth 2000;12:308-14.

45. Meliones JN, Bove EL, Dekeon MK, et al. Highfrequency jet ventilation improves cardiac function after the Fontan procedure. Circulation 1991;84:III364-8.

46. Otto CW, Quan SF, Conahan TJ, et al. Hemodynamic effects of high-frequency jet ventilation. Anesth Analg 1983;62:298-304.

47. Zobel G, Dacar D, Rodl S. Hemodynamic effects of different modes of mechanical ventilation in acute cardiac and pulmonary failure: an experimental study. Crit Care Med 1994;22:1624-30.

48. Kuluz MA, Smith PB, Mears SP, et al. Preliminary observations of the use of high-frequency jet ventilation as rescue therapy in infants with congenital diaphragmatic hernia. J Pediatr Surg 2010;45:698-702.

49. Attar MA, Dechert RE, Donn SM. Rescue high frequency ventilation for congenital diaphragmatic hernia. J Neonatal Perinatal Med 2019;12:173-8.

50. O'Toole SJ, Irish MS, Holm BA, et al. Pulmonary vascular abnormalities in congenital diaphragmatic hernia. Clin Perinatol 1996;23:781-94.

51. Yamataka T, Puri P. Pulmonary artery structural changes in pulmonary hypertension complicating congenital diaphragmatic hernia. J Pediatr Surg 1997;32:387-90.

52. Sluiter I, van der Horst I, van der Voorn P, et al. Premature differentiation of vascular smooth muscle cells in human congenital diaphragmatic hernia. Exp Mol Pathol 2013;94:195-202.

53. Schmidt AF, Rojas-Moscoso JA, Goncalves FL, et al. Increased contractility and impaired relaxation of the left pulmonary artery in a rabbit model of congenital diaphragmatic hernia. Pediatr Surg Int 2013;29:489-94.

54. Luong C, Rey-Perra J, Vadivel A, et al. Antenatal sildenafil treatment attenuates pulmonary hypertension in experimental congenital diaphragmatic hernia. Circulation 2011;123:2120-31.

55. Shehata SM, Sharma HS, Mooi WJ, et al. Pulmonary hypertension in human newborns with congenital diaphragmatic hernia is associated with decreased vascular 
expression of nitric-oxide synthase. Cell Biochem Biophys 2006;44:147-55.

56. Solari V, Piotrowska AP, Puri P. Expression of heme oxygenase- 1 and endothelial nitric oxide synthase in the lung of newborns with congenital diaphragmatic hernia and persistent pulmonary hypertension. J Pediatr Surg 2003;38:808-13.

57. Mous DS, Buscop-van Kempen MJ, Wijnen RMH, et al. Changes in vasoactive pathways in congenital diaphragmatic hernia associated pulmonary hypertension explain unresponsiveness to pharmacotherapy. Respir Res 2017;18:187.

58. Sood BG, Wykes S, Landa M, et al. Expression of eNOS in the lungs of neonates with pulmonary hypertension. Exp Mol Pathol 2011;90:9-12.

59. Nakamura H, Zimmer J, Friedmacher F, et al. Expression of Nitric Oxide Synthase Interacting Protein (NOSIP) is Decreased in the Pulmonary Vasculature of NitrofenInduced Congenital Diaphragmatic Hernia. Eur J Pediatr Surg 2019;29:102-7.

60. Karamanoukian HL, Glick PL, Zayek M, et al. Inhaled nitric oxide in congenital hypoplasia of the lungs due to diaphragmatic hernia or oligohydramnios. Pediatrics 1994;94:715-8.

61. Shah N, Jacob T, Exler R, et al. Inhaled nitric oxide in congenital diaphragmatic hernia. J Pediatr Surg 1994;29:1010-4; discussion 1014-5.

62. NINOS. Inhaled nitric oxide and hypoxic respiratory failure in infants with congenital diaphragmatic hernia. The Neonatal Inhaled Nitric Oxide Study Group (NINOS). Pediatrics 1997;99:838-45.

63. Putnam LR, Tsao K, Morini F, et al. Evaluation of Variability in Inhaled Nitric Oxide Use and Pulmonary Hypertension in Patients With Congenital Diaphragmatic Hernia. JAMA Pediatr 2016;170:1188-94.

64. Herich K, Schaible T, Reinhard J, et al. iNO Therapy in Patients with Congenital Diaphragmatic Hernia Discrepancy between Widespread Use and Therapeutic Effects. Klin Padiatr 2019;231:320-5.

65. Kinsella JP, Parker TA, Ivy DD, et al. Noninvasive delivery of inhaled nitric oxide therapy for late pulmonary hypertension in newborn infants with congenital diaphragmatic hernia. J Pediatr 2003;142:397-401.

66. Lawrence KM, Berger K, Herkert L, et al. Use of prostaglandin E1 to treat pulmonary hypertension in congenital diaphragmatic hernia. J Pediatr Surg 2019;54:55-9.

67. Vukcevic Z, Coppola CP, Hults C, et al. Nitrovasodilator responses in pulmonary arterioles from rats with nitrofeninduced congenital diaphragmatic hernia. J Pediatr Surg 2005;40:1706-11.

68. Bialkowski A, Moenkemeyer F, Patel N. Intravenous sildenafil in the management of pulmonary hypertension associated with congenital diaphragmatic hernia. Eur J Pediatr Surg 2015;25:171-6.

69. Noori S, Friedlich P, Wong P, et al. Cardiovascular effects of sildenafil in neonates and infants with congenital diaphragmatic hernia and pulmonary hypertension. Neonatology 2007;91:92-100.

70. Kipfmueller F, Schroeder L, Berg C, et al. Continuous intravenous sildenafil as an early treatment in neonates with congenital diaphragmatic hernia. Pediatr Pulmonol 2018;53:452-60.

71. Cochius-den Otter S, Schaible T, Greenough A, et al. The CoDiNOS trial protocol: an international randomised controlled trial of intravenous sildenafil versus inhaled nitric oxide for the treatment of pulmonary hypertension in neonates with congenital diaphragmatic hernia. BMJ Open 2019;9:e032122.

72. Stocker C, Penny DJ, Brizard CP, et al. Intravenous sildenafil and inhaled nitric oxide: a randomised trial in infants after cardiac surgery. Intensive Care Med 2003;29:1996-2003.

73. Hoffman TM, Wernovsky G, Atz AM, et al. Prophylactic intravenous use of milrinone after cardiac operation in pediatrics (PRIMACORP) study. Prophylactic Intravenous Use of Milrinone After Cardiac Operation in Pediatrics. Am Heart J 2002;143:15-21.

74. James AT, Corcoran JD, McNamara PJ, et al. The effect of milrinone on right and left ventricular function when used as a rescue therapy for term infants with pulmonary hypertension. Cardiol Young 2016;26:90-9.

75. McNamara PJ, Shivananda SP, Sahni M, et al. Pharmacology of milrinone in neonates with persistent pulmonary hypertension of the newborn and suboptimal response to inhaled nitric oxide. Pediatr Crit Care Med 2013;14:74-84.

76. El-Khuffash A, McNamara PJ, Breatnach C, et al. The use of milrinone in neonates with persistent pulmonary hypertension of the newborn - a randomised controlled trial pilot study (MINT 1): study protocol and review of literature. Matern Health Neonatol Perinatol 2018;4:24.

77. Patel N. Use of milrinone to treat cardiac dysfunction in infants with pulmonary hypertension secondary to congenital diaphragmatic hernia: a review of six patients. Neonatology 2012;102:130-6. 
78. Kumar VHS, Dadiz R, Koumoundouros J, et al. Response to pulmonary vasodilators in infants with congenital diaphragmatic hernia. Pediatr Surg Int 2018;34:735-42.

79. Mears M, Yang M, Yoder BA. Is Milrinone Effective for Infants with Mild-to-Moderate Congenital Diaphragmatic Hernia? Am J Perinatol 2020;37:258-63.

80. Lakshminrusimha S, Keszler M, Kirpalani H, et al. Milrinone in congenital diaphragmatic hernia - a randomized pilot trial: study protocol, review of literature and survey of current practices. Matern Health Neonatol Perinatol 2017;3:27.

81. de Lagausie P, de Buys-Roessingh A, Ferkdadji L, et al. Endothelin receptor expression in human lungs of newborns with congenital diaphragmatic hernia. J Pathol 2005;205:112-8.

82. Keller RL, Tacy TA, Hendricks-Munoz K, et al. Congenital diaphragmatic hernia: endothelin-1, pulmonary hypertension, and disease severity. Am J Respir Crit Care Med 2010;182:555-61.

83. Mohamed WA, Ismail M. A randomized, double-blind, placebo-controlled, prospective study of bosentan for the treatment of persistent pulmonary hypertension of the newborn. J Perinatol 2012;32:608-13.

84. Olson E, Lusk LA, Fineman JR, et al. Short-Term Treprostinil Use in Infants with Congenital Diaphragmatic Hernia following Repair. J Pediatr 2015;167:762-4.

85. Bos AP, Tibboel D, Koot VC, et al. Persistent pulmonary hypertension in high-risk congenital diaphragmatic hernia patients: incidence and vasodilator therapy. J Pediatr Surg 1993;28:1463-5.

86. Carpentier E, Mur S, Aubry E, et al. Safety and tolerability of subcutaneous treprostinil in newborns with congenital diaphragmatic hernia and life-threatening pulmonary hypertension. J Pediatr Surg 2017;52:1480-3.

87. Betremieux P, Gaillot T, de la Pintiere A, et al. Congenital diaphragmatic hernia: prenatal diagnosis permits immediate intensive care with high survival rate in isolated cases. A population-based study. Prenat Diagn 2004;24:487-93.

88. Lawrence KM, Hedrick HL, Monk HM, et al. Treprostinil Improves Persistent Pulmonary Hypertension Associated with Congenital Diaphragmatic Hernia. J Pediatr 2018;200:44-9.

89. Mohseni-Bod H, Bohn D. Pulmonary hypertension in congenital diaphragmatic hernia. Semin Pediatr Surg 2007;16:126-33.

90. Shiyanagi S, Okazaki T, Shoji H, et al. Management of pulmonary hypertension in congenital diaphragmatic hernia: nitric oxide with prostaglandin-E1 versus nitric oxide alone. Pediatr Surg Int 2008;24:1101-4.

91. Yu PT, Jen HC, Rice-Townsend S, et al. The role of ECMO in the management of congenital diaphragmatic hernia. Semin Perinatol 2020;44:151166.

92. Kays DW. ECMO in CDH: Is there a role? Semin Pediatr Surg 2017;26:166-70.

93. Cairo SB, Arbuthnot M, Boomer LA, et al. Controversies in extracorporeal membrane oxygenation (ECMO) utilization and congenital diaphragmatic hernia (CDH) repair using a Delphi approach: from the American Pediatric Surgical Association Critical Care Committee (APSA-CCC). Pediatr Surg Int 2018;34:1163-9.

94. Kim AG, Mon R, Karmakar M, et al. Predicting lethal pulmonary hypoplasia in congenital diaphragmatic hernia (CDH): Institutional experience combined with $\mathrm{CDH}$ registry outcomes. J Pediatr Surg 2020. [Epub ahead of print].

95. Kim AG, Karmakar M, Lally PA, et al. Evaluating Lethal Pulmonary Hypoplasia in the CDH Registry. Pediatrics 2020;146:667-8.

96. Dimmitt RA, Moss RL, Rhine WD, et al. Venoarterial versus venovenous extracorporeal membrane oxygenation in congenital diaphragmatic hernia: the Extracorporeal Life Support Organization Registry, 1990-1999. J Pediatr Surg 2001;36:1199-204.

97. Guner YS, Khemani RG, Qureshi FG, et al. Outcome analysis of neonates with congenital diaphragmatic hernia treated with venovenous vs venoarterial extracorporeal membrane oxygenation. J Pediatr Surg 2020;5 5:2618-24.

98. Heiss KF. Congenital diaphragmatic hernia in 1994: a hard look at the need for 'emergency surgery'. Semin Thorac Cardiovasc Surg 1994;6:221-7.

99. Kugelman A, Gangitano E, Pincros J, et al. Venovenous versus venoarterial extracorporeal membrane oxygenation in congenital diaphragmatic hernia. J Pediatr Surg 2003;38:1131-6.

100. Guner YS, Harting MT, Fairbairn K, et al. Outcomes of infants with congenital diaphragmatic hernia treated with venovenous versus venoarterial extracorporeal membrane oxygenation: A propensity score approach. J Pediatr Surg 2018;53:2092-9.

101. Wynn J, Krishnan U, Aspelund G, et al. Outcomes of congenital diaphragmatic hernia in the modern era of management. J Pediatr 2013;163:114-9.e1.

102.Ijsselstijn H, van Heijst AF. Long-term outcome of children treated with neonatal extracorporeal membrane oxygenation: increasing problems with increasing age. 
Semin Perinatol 2014;38:114-21.

103. Church JT, Mon R, Wright T, et al. Neurodevelopmental outcomes in CDH survivors: A single institution's experience. J Pediatr Surg 2018;53:1087-91.

104. Moyer V, Moya F, Tibboel R, et al. Late versus early surgical correction for congenital diaphragmatic hernia in newborn infants. Cochrane Database Syst Rev 2000;(3):CD001695.

105. Hollinger LE, Lally PA, Tsao K, et al. A risk-stratified analysis of delayed congenital diaphragmatic hernia repair: does timing of operation matter? Surgery 2014;156:475-82.

106. Dassinger MS, Copeland DR, Gossett J, et al. Early repair of congenital diaphragmatic hernia on extracorporeal membrane oxygenation. J Pediatr Surg 2010;45:693-7.

107.Desai AA, Ostlie DJ, Juang D. Optimal timing of congenital diaphragmatic hernia repair in infants on extracorporeal membrane oxygenation. Semin Pediatr Surg 2015;24:17-9.

108. Fallon SC, Cass DL, Olutoye OO, et al. Repair of congenital diaphragmatic hernias on Extracorporeal Membrane Oxygenation (ECMO): does early repair improve patient survival? J Pediatr Surg 2013;48:1172-6.
109. Glenn IC, Abdulhai S, Lally PA, et al. Early CDH repair on ECMO: Improved survival but no decrease in ECMO duration (A CDH Study Group Investigation). J Pediatr Surg 2019;54:2038-43.

110.Dao DT, Burgos CM, Harting MT, et al. Surgical Repair of Congenital Diaphragmatic Hernia After Extracorporeal Membrane Oxygenation Cannulation: Early Repair Improves Survival. Ann Surg 2019. [Epub ahead of print].

111. Delaplain PT, Harting MT, Jancelewicz T, et al. Potential survival benefit with repair of congenital diaphragmatic hernia $(\mathrm{CDH})$ after extracorporeal membrane oxygenation (ECMO) in select patients: Study by ELSO CDH Interest Group. J Pediatr Surg 2019;54:1132-7.

112. Partridge EA, Peranteau WH, Rintoul NE, et al. Timing of repair of congenital diaphragmatic hernia in patients supported by extracorporeal membrane oxygenation (ECMO). J Pediatr Surg 2015;50:260-2.

113. Kays DW, Talbert JL, Islam S, et al. Improved Survival in Left Liver-Up Congenital Diaphragmatic Hernia by Early Repair Before Extracorporeal Membrane Oxygenation: Optimization of Patient Selection by Multivariate Risk Modeling. J Am Coll Surg 2016;222:459-70.
Cite this article as: Yang MJ, Russell KW, Yoder BA, Fenton SJ. Congenital diaphragmatic hernia: a narrative review of controversies in neonatal management. Transl Pediatr 2021;10(5):1432-1447. doi: 10.21037/tp-20-142 